\title{
Pluralismo e liberdade no pensamento político liberal - Locke, Stuart Mill e Isaiah Berlin'1
}

\author{
Márcio Rodrigues Barboza ${ }^{2}$
}

\section{Resumo}

O presente trabalho visa a explorar o tema da pluralidade social e política nas obras de três autores identificados com a tradição liberal do pensamento político, a saber: Jonh Locke, Jonh Stuart Mill e Isaiah Berlin. Pretendemos identificar as afinidades e as diferenças destes em relação ao tema em questão, o que nos permitirá explorar conceitualmente a própria tradição a que pertencem.

Para tanto, analisaremos as obras paradigmáticas dos autores mencionados, além de outros materiais disponíveis em português e em castelhano que tratam do problema da pluralidade social na tradição liberal.

O método comparativo apresenta-se como o mais adequado, uma vez que, por meio do contraste, permitir-nos-á identificar as contribuições originais de cada autor referentes ao pluralismo social e político, sem perder de vista o que têm em comum.

Como já se terá percebido, trata-se de trabalho situado entre a história das ideias políticas e a teoria política normativa, que, sob a perspectiva do liberalismo político, recoloca a clássica questão de filosofia política desde a Antiguidade: quais as características de um regime político ideal?

\footnotetext{
${ }^{1}$ Resumo do Projeto de Pesquisa apresentado à Universidade Federal de São Paulo (Unifesp), aprovado na seleção de bolsistas pelo Programa Institucional de Bolsas de Iniciação Científica (PIBIC - 2014/2015)

2 marciobalzac@gmail.com - Universidade Federal de São Paulo - UNIFESP, Escola de Filosofia, Letras e Ciências Humanas, Departamento de Ciências Sociais, Campus Guarulhos. Orientador: Prof. Doutor Júlio César Casarin Barroso Silva
} 
Palavras Chave: pluralismo político e social, liberalismo político, tolerância, liberdades civis, teoria política

\section{Introdução e Justificativa}

O contato com correntes teóricas divergentes em relação ao valor dado à pluralidade social e política representa o ponto de partida do presente trabalho. O liberalismo político apresenta-se como o modelo mais apropriado para a análise do pluralismo, porém mesmo na tradição liberal as ideias referentes à pluralidade não são homogêneas.

Por pluralismo social entendemos aqui tanto a pluralidade de interesses quanto a pluralidade de visões de mundo encontráveis nas sociedades contemporâneas. Segundo Rawls (2000, p. 80):

[...] a diversidade de doutrinas compreensivas, religiosas, filosóficas e morais, que encontramos nas sociedades democráticas modernas, não constituem uma mera situação histórica que repentinamente poderá terminar; é uma característica permanente da cultura pública da democracia. Nas condições políticas e sociais que asseguram os direitos e as liberdades básicas de instituições livres, uma diversidade de doutrinas compreensivas opostas e inconciliáveis surgirá e persistirá, se é que tal diversidade já não está ocorrendo.

Por pluralismo político entendemos a representação da pluralidade social nas instituições políticas da sociedade. Definido o conceito que será utilizado na pesquisa, é conveniente traçar um panorama, além de justificar a escolha do referencial teórico adotado. O liberalismo político constitui uma doutrina política que reconhece o valor da pluralidade, por isso, interessa-se 
pelos arranjos que melhor permitem o florescimento dela (como um conjunto de direitos civis e políticos básicos, por exemplo). Nesse ponto, como veremos ao longo da pesquisa, o liberalismo contrasta com versões do republicanismo e da tradição comunitarista, as quais lidam com o fato do pluralismo com mais dificuldade.

Evidentemente, há muitos liberalismos políticos. Mas qualquer versão desta doutrina política deve incluir os seguintes elementos: a) a limitação das funções e poderes do Estado; b) Defesa da dispersão da soberania e c) a afirmação de uma soberania ética do individuo em determinados âmbitos. Todos esses itens de uma forma ou de outra contribuem para o florescimento da pluralidade social.

\section{Sobre os Autores Escolhidos}

Como dito na introdução, nossa proposta será a análise dos argumentos de autores filiados à tradição liberal no que tange à forma como estes tratam a questão do pluralismo. Os autores em questão são Jonh Locke (1632-1704), Jonh Stuart Mill (1806-1873) e Isaiah Berlin (1909-1997).

Jonh Locke faz parte dos filósofos do jusnaturalismo e portanto, pontua como alguns direitos inerentes a qualquer individuo devem configurar como uma barreira ao poder do Estado. Para o filósofo inglês, antes da sociedade civil, cuja existência só se justifica porque nela a proteção dos direitos naturais se dá com maior eficiência, os homens gozavam do direito à propriedade que representava, para além dos bens materiais, a vida e a liberdade.

A limitação do Estado às funções outorgadas pela sociedade com base nos direitos naturais constitui um dos elementos que associam Locke à 
tradição liberal. $\mathrm{O}$ autor é um dos primeiros a defender a tolerância religiosa (e portanto, a pluralidade social nos assuntos concernentes à religião, assunto no qual o governante não pode envolver-se a seu bel-prazer).

Na obra Cartas sobre a Tolerancia (1994), Locke explica como a ação do magistrado civil em relação a questões religiosas é ilegítima, pois a este, cabe legislar sobre questões relacionadas à manutenção da ordem da sociedade civil e não imiscuir-se nos assuntos da "alma", controlar a liberdade de consciência não compete ao magistrado (nem aos membros de uma religião circunstancialmente dominante). $\mathrm{O}$ individuo deve ser livre para adotar a religião que lhe convier.

Os limites da ação do Estado e da sociedade em relação ao individuo também são tratados por Jonh Stuart Mill (1806-1873) em duas de suas obras: "Sobre a Liberdade" (1859) e "Considerações sobre o Governo Representativo" (1861). Na primeira obra citada, o objetivo consiste na definição de princípios necessários à proteção da liberdade "negativa" ${ }^{3}$, ou seja, aquela que trata do espaço no qual o indivíduo não está constrangido a fazer o que não quer ou que não há obstrução à conduta individual. $\mathrm{Na}$ segunda, Mill defende a construção de mecanismos institucionais que garantam a representação de minorias políticas. As duas obras serão utilizadas no presente estudo.

Isaiah Berlin.

É na obra Dois Conceitos de Liberdade que encontramos a análise das duas acepções da palavra liberdade: a "negativa" e a "positiva", o ensaio surgiu modestamente (fruto de uma aula inaugural da disciplina de teoria política na Universidade de Oxford ministrada em 1958), porém sua

${ }^{3} \mathrm{O}$ termo liberdade negativa não é atribuído à Mill, surgiu no ensaio "Dois Conceitos de Liberdade" de Isaiah Berlin 
influencia foi enorme para a teoria política, as duas noções implicam em diferentes modos de tratar a pluralidade.

A liberdade "negativa", grosso modo, refere-se aos ambitos nos quais o individuo é soberano, ou seja, dos espaços da vida individual nos quais o sujeito não deve sofrer coerção tanto do estado como da sociedade para agir conforme o modo considerado correto.

A liberdade "positiva" apresenta duas dimensões: a primeira diz respeito a uma orientação ética por parte do individuo, esta dimensão afirma que existem paixões e inclinações individuais baseadas em superstições que escravizam o sujeito e comumente induzem o ser humano ao erro. Alcançar a liberdade positiva, o desejo de não ser dominado por nada, nem ninguém, seria a tarefa de todo o homem disposto a libertar-se das grosseiras paixões desenfreadas, para tanto é preciso o reencontro com o "verdadeiro-eu", essa "entidade" maior e melhor do que o eu cotidiano escravizado pela busca das satisfações imediatas, surge quando o individuo reencontra e desenvolve seu aspecto racional.

O problema consiste na segunda dimensão relacionada a essa visão de liberdade: quando relacionada ao campo social e político, tal doutrina pode ser muito perigosa. Ao aceitar afastar as minhas convicções por serem não racionais, transfiro a outra entidade o papel de mostrar-me o verdadeiro "eu". Estados autoritários, segundo Berlin, ganharam legitimidade com esse tipo de discurso.

Essa liberdade "positiva" muitas vezes abre as portas para que os homens sejam tratados como não humanos, pois para alguns, como Kant (com quem Berlin tende a concordar nesse aspecto), por ser o homem criador de valores, é a liberdade que nos faz humanos. Tratar os homens como 
sujeitos a qualquer tipo de influencia externa "é negar a essência humana deles, é tratá-los como objetos sem vontade própria e, portanto, degradá-los”.

Implicações políticas originam-se desse tipo de doutrina, afinal aqueles que já conhecem a verdade racional e por isso estão aptos a guiaremse sem risco de erros pelo mundo podem acreditar que é preciso fazer dos outros membros da sociedade também seres "livres", já que a maioria dos homens não podem permanecer como vítimas dos próprios desejos errôneos.

\section{Referências}

ARAUjO, Cicero. Concepções do Mundo e o Fato do Pluralismo. Instituto de Estudos Avançados da Universidade de São Paulo, São Paulo, 2013. Disponível em www.iea.usp/publicacoes/textos/araujopluralismo.pdf. Acesso em 15 março, 2014

BERLIN, Isaiah. Estudos sobre a Humanidade. Uma Antologia de Ensaios. editado por Henry Hardy e Roger Hausheer: Prefácio de Noel Annan e introdução de Roger Hausheer; Tradução Rosaura Eichenberg. São Paulo: Companhia das Letras, 2002, (pgs. 11-39; 226-272).

BOBBIO, Norberto. Liberalismo e Democracia. $6^{a}$ ed. $6^{a}$ reimpressão. Tradução Marco Aurelio Nogueira. São Paulo: Brasiliense, 2006

LOCKE, Jonh. Cartas sobre a tolerância. In: Segundo Tratado sobre o Governo civil e outros escritos. Introdução de J.W. Gough; Tradução de Magda Soares e Marisa Lobo da Costa. 3ª ed. Rio de Janeiro: Ed. Vozes, 1994.

MILL, Jonh Stuart. Considerações sobre o Governo Representativo. Brasilia. UNB, 1981

MII, Jonh Stuart. Sobre a Liberdade. Petrópolis. Editora Vozes. 1991

RAWLS, Jonh. O liberalismo político. São Paulo, Atica, 2000

ROUSSEAU, Jean Jacques. O contrato social. Tradução Antonio de Pádua Danesi. $3^{\text {a }}$ Ed. - São Paulo: Martins Fontes, 1996 (pg. 25-26)

WELFORT, Francisco C. (Org). Os clássicos da política: Maquiavel, Hobbes, Locke, Montesquieu, Rousseau, O Federalista. São Paulo: Atica, 2002. 13 a ed. V. 1 (pgs. 79$110 ; 187-201)$ 
WELFORT, Francisco C. (Org). Os clássicos da política: Burke, Kant, Hegel,

Tocqueville, Stuart Mill, Marx. 11 a ed. São Paulo: Atica, 2006. V.2 (pgs. 189-223)

SALAZAR, Fernanda Maria Gundes. Sistemas eleitorais: uma introdução. VIAjus, 14/03/2006. Disponível em

http://www.viajus.com.br/viajus.php?pagina=artigos\&id=400. Acesso em 18 março. 2014 